$\begin{array}{ll} & \text { Etnográfica } \\ \text { etnográfica } & \text { Revista do Centro em Rede de Investigação em }\end{array}$

Antropologia

vol. $14(3) \mid 2010$

Vol. $14(3)$

\title{
Kimberly DaCosta Holton e Andrea Klimt (orgs.), Community, Culture and the Makings of Identity: Portuguese-Americans Along the Eastern Seaboard
}

\section{Marta Vilar Rosales}

\section{OpenEdition}

\section{Journals}

\section{Edição electrónica}

URL: https://journals.openedition.org/etnografica/235

DOI: 10.4000/etnografica.235

ISSN: 2182-2891

\section{Editora}

Centro em Rede de Investigação em Antropologia

Edição impressa

Data de publição: 1 outubro 2010

Paginação: 617-630

ISSN: 0873-6561

\section{Refêrencia eletrónica}

Marta Vilar Rosales, «Kimberly DaCosta Holton e Andrea Klimt (orgs.), Community, Culture and the Makings of Identity: Portuguese-Americans Along the Eastern Seaboard》, Etnográfica [Online], vol. 14 (3) I 2010, posto online no dia 20 julho 2012, consultado o 12 fevereiro 2022. URL: http://

journals.openedition.org/etnografica/235 ; DOI: https://doi.org/10.4000/etnografica.235

Este documento foi criado de forma automática no dia 12 fevereiro 2022.

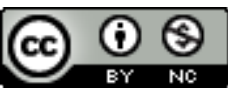

Etnográfica is licensed under a Creative Commons Attribution-NonCommercial 4.0 International License. 


\title{
Kimberly DaCosta Holton e Andrea Klimt (orgs.), Community, Culture and the Makings of Identity: Portuguese- Americans Along the Eastern Seaboard
}

\author{
Marta Vilar Rosales
}

\section{REFERÊNCIA}

Kimberly DaCosta Holton e Andrea Klimt (orgs.), Community, Culture and the Makings of Identity: Portuguese-Americans Along the Eastern Seaboard, Dartmouth, University of Massachusetts, 650 páginas. 2009

1 Community, Culture and the Makings of Identity, organizado por Kimberly DaCosta Holton e Andrea Klimt constitui um volume de dimensão considerável que reúne um conjunto de reflexões acerca das populações de origem portuguesa, angolana, brasileira e caboverdiana que migraram para a costa leste dos Estados Unidos da América.

2 De acordo com o exposto na introdução, o livro resulta de um conjunto de debates académicos e propõe-se, enquanto projecto inovador, contribuir para a ultrapassagem da dicotomia que perspectiva as migrações do último século para os EUA, opondo as vagas ocorridas no início do século aos movimentos mais recentes situados no quadro pós-colonial. Contrariando as lógicas de migrações com origem noutros contextos, as migrações portuguesas são apresentadas como movimentos mais ou menos permanentes, envolvendo diferentes classes sociais, origens geográficas e sectores da sociedade portuguesa do século XX. Possibilitar a emergência de uma discussão ampla, profunda e plural sobre os "portugueses da costa nordeste" justifica a integração no livro de contributos que exploram as intersecções das experiências destes migrantes com "as comunidades de brasileiros, cabo-verdianos e retornados africanos" que povoam igualmente a região. Sublinha-se ainda a necessidade de discutir as 
potencialidades e os limites criados pelas condições políticas, económicas e materiais enquanto factores-chave na construção de trajectórias individuais, familiares e comunitárias, face a perspectivas que privilegiam a cultura como factor explicativo, bem como a importância de se explorarem as valências analíticas das interconexões existentes entre contexto e cultura, global e local, continuidade e mudança, sistemas de valores e práticas quotidianas.

Dos vinte textos que compõem o livro, onze são versões revistas e/ou traduzidas de textos anteriormente publicados. Relativamente aos autores que contribuem para a obra (maioritariamente antropólogos e sociólogos norte-americanos), é de referir a presença de nomes cujos trabalhos constituem contributos incontornáveis para o estudo das migrações portuguesas.

Os textos encontram-se organizados em cinco temáticas. A primeira, "cidadania, pertença e comunidade", integra três reflexões que promovem a discussão dos temas enunciados partindo de uma estratégia comum: a desconstrução de estereótipos dominantes que pairam sobre os portugueses na América. Bloemraad questiona a pretensamente inevitável "invisibilidade política" dos portugueses no Canadá e nos EUA, desafiando as representações que a atribuem exclusivamente aos baixos níveis de escolaridade e às políticas repressivas do Estado Novo. Argumenta que estes obstáculos se conjugam com outros impedimentos resultantes dos quadros legais e das políticas institucionais promovidas pelos contextos de acolhimento. Feldman-Bianco parte do conceito de saudade e do lugar que este ocupa na definição essencializada "da alma e do carácter portugueses" para discutir as apropriações e conceptualizações diferenciadas a que o mesmo foi sujeito pelo Estado Novo na construção de uma noção de nação desterritorializada e pelos migrantes na gestão das suas identidades individuais e colectivas. Klimt conclui o grupo com um contributo centrado nas assunções reificadas existentes sobre a "evolução natural" das comunidades portuguesas migrantes, sobretudo no que respeita às estratégias de relacionamento com os contextos de acolhimento e de origem. Confrontando grupos radicados nos EUA e na Alemanha, conclui que as identidades colectivas e as políticas de desenvolvimento comunitário são processos contingentes, historicamente específicos e dependentes de factores conjunturais, tais como as oportunidades de emprego, os contextos ideológicos e legais ou as condições objectivas de instalação no destino.

5 A segunda temática, "cultura expressiva, representações nos media e identidade", integra seis contributos. Leal explora a dialéctica entre continuidade e mudança, tradição e inovação no quadro dos impérios marienses nos EUA. Apesar de a tradição ser evidente na construção identitária migrante, o seu texto reclama igual centralidade para a função desempenhada pelos impérios na sua tradução e adequação a novas formas de sociabilidade e estilos de vida decorrentes do contexto americano. Holton discute o conceito de aculturação selectiva proposto por Portes, através da observação das lógicas que estruturam os ranchos folclóricos na diáspora. Veículo de ligação económica e emocional à origem, o folclore parece suportar as políticas de e/imigração portuguesa e americana, ao estimular o uso da língua e dos valores da origem e promover a endogamia, ao mesmo tempo que celebra o sucesso comercial a ele aliado e aumenta a visibilidade política do grupo. A negociação das identidades étnica, social e política através da cultura expressiva é igualmente abordada por Batista, num artigo sobre uma exposição de "imagens da Virgem Maria na arte portuguesa" organizada por um museu em Newark, e também por Brucher, ao analisar a viagem de uma banda 
musical luso--americana a dois municípios portugueses. Correia e De Almeida centramse na análise dos discursos jornalísticos. Abordando dois casos distintos, ambos discutem as potencialidades e efeitos dos media no quadro da vida comunitária migrante.

6 A terceira temática, "educação, mobilidade social e cultura política", integra três contributos. Sá e Borges desafiam as explicações dominantes que atribuem a relativa falta de mobilidade social dos migrantes portugueses aos seus capitais culturais baixos e pouca valorização da escola, chamando a atenção para as barreiras instituídas pelos contextos laborais, escolares e sociais, os quais contribuem, em grande medida, para a reprodução do quadro. Barrow contesta também as explicações deterministas que a atribuem à fraca participação política dos portugueses, argumentando que a aparente inexistência de uma agenda política portuguesa se deve menos aos níveis de participação política apresentados do que a impedimentos estruturais que impossibilitam a sua emergência. Becker retoma a problemática do relacionamento com a escola, discutindo as dificuldades existentes na gestão da identidade étnica num quadro em que simultaneamente se promove a valorização da cultura anglo-saxónica e se rejeita a identificação com a mesma por parte das crianças migrantes.

7 A quarta temática, "trabalho, género e família", inclui também três reflexões. Reeve retoma a discussão da participação dos portugueses, neste caso, nas estruturas sindicais. A partir de um estudo realizado numa unidade industrial na primeira metade do século XX, o estereótipo da fraca participação é desafiado por um registo que dá conta de um envolvimento muito significativo das mulheres portuguesas, inclusive em posições de liderança. 0 elevado nível de sindicalização apresentado pelas portuguesas constitui igualmente o campo de discussão do artigo desenvolvido por Bookman. De acordo com a autora, os argumentos que sustentam a ideia de que haveria uma fraca participação sindical feminina - representações de género tradicionais e forte identidade étnica - são, em grande parte, os factores responsáveis por uma elevada sindicalização efectiva das mulheres. Lamphere, Silva e Sousa desenvolvem uma reflexão em torno dos efeitos da proletarização na estrutura das unidades familiares e na gestão das redes de parentesco da população migrante que se encontrava maioritariamente ligada ao sector primário em Portugal.

8 A última temática, "raça, pós-colonialismo e contextos diaspóricos", integra cinco artigos que, por transcenderem o campo das migrações portuguesas, complexificam a discussão apresentada. Moniz analisa o processo de constituição e reconhecimento formal de grupos minoritários na América como ponto de partida para discutir a natureza maleável da categorização étnica e racial portuguesa. Clarificando as intersecções existentes entre a construção e gestão das categorias raça e etnicidade e o sistema legal, demonstra que o não-reconhecimento dos portugueses enquanto minoria étnica não preveniu a sua sujeição aos mesmos mecanismos de exclusão a que foram sujeitas outras minorias legalmente reconhecidas, retirando-lhes, no entanto, a possibilidade de poderem contar com a protecção legal que esse reconhecimento proporciona. Ramos-Zayas examina a produção quotidiana da diferença à medida que esta é transformada em categorizações rígidas. A partir do estudo de caso de um grupo de jovens mulheres brasileiras que residem na "Newark portuguesa", discute os processos de formação de estereótipos e os modos como estes se cruzam e interferem no campo das relações laborais, promovendo tensões sociais. Gibau observa os processos de negociação identitária dos cabo-verdianos nos EUA, contexto onde a raça 
constitui um mecanismo de categorização formal importante. Holton propõe um artigo em que se desafia a tese da assimilação positiva dos retornados de África pela sociedade portuguesa pós-colonial. Partindo de um conjunto restrito de histórias de vida, discute os motivos que os levaram a concretizar mais uma migração que os afasta de Portugal e os modos como a sua experiência colonial anterior se faz sentir nas relações que estabelecem com outros grupos étnicos no novo contexto. Halter finaliza o grupo com uma reflexão que confronta dois fluxos migratórios cabo--verdianos, um no final do século XIX e o segundo no período pós-independência. Partindo de um conjunto significativo de tópicos, a autora demonstra a complexidade que marca, na contemporaneidade, o domínio das relações pós-coloniais entre cabo-verdianos, portugueses e brasileiros no contexto norte-americano.

9 A última nota desta recensão vai para a bibliografia que integra a obra. Organizada a partir das referências utilizadas pelo grupo de autores publicados, constitui um recurso importante para todos os que investigam e reflectem sobre as migrações portuguesas em geral e, especialmente, sobre as que tiveram como destino a costa nordeste dos Estados Unidos da América.

\section{AUTORES}

\section{MARTA VILAR ROSALES}

CRIA/FCSH-UNL 